\title{
Estudio prospectivo sobre muerte súbita de origen cardiovascular en niños y adultos jóvenes
}

\author{
A prospective study of sudden cardiac death among children and young adults
}

\section{Objetivos}

Evaluar la incidencia de Muerte Súbita (MS) de origen cardíaco entre niños y adultos jóvenes.

\section{Diseño, lugar y pacientes}

Cohorte prospectivo, basado en la población, realizado en Australia y Nueva Zelanda entre Enero de 2010 y Diciembre de 2012. Se recopiló información clínica, demográfica, genética y de autopsia sobre casos de muerte cardíaca súbita en niños y adultos jóvenes de 1 a 35 años.

En los casos que no se obtuvo causa identificada (muerte cardíaca súbita inexplicada), aún después de una autopsia exhaustiva que incluía estudios toxicológicos e histológicos, se analizaron genes cardíacos para evaluar una mutación genética cardíaca clínicamente relevante.

Además se realizó seguimiento clínico de los familiares de primer orden de la víctima.
Bagnall R.D y col. N Engl J Med 2016;374:2441-52

\section{Resultados}

Se identificaron 490 casos de MS cardíaca en los tres años evaluados. La incidencia anual fue de 1,3 casos por 100.000 personas de 1 a 35 años de edad. Las personas de 31 a 35 años de edad tuvieron la mayor incidencia de muerte súbita cardíaca $(3,2$ casos por 100.000 personas al año) y las personas de 16 a 20 años de edad tuvieron la mayor incidencia de muerte cardíaca súbita inexplicable $(0,8$ casos por 100.000 personas al año). Las causas principales fueron la enfermedad coronaria adquirida (24\% de los casos) y las cardiomiopatías hereditarias $(16 \%$ de los casos). Se identificó una mutación genética cardíaca clínicamente relevante en 31 de 113 casos $(27 \%)$ de muerte cardíaca súbita inexplicable en la que se realizó la prueba genética. Durante el seguimiento, se llegó a un diagnóstico clínico de enfermedad cardiovascular en el $13 \%$ de las familias (familiar de primer orden) en las que ocurrió una muerte súbita cardíaca de causa no definida. En la Tabla 1 se resumen las principales características de la cohorte.

Tabla 1. Características clínicas y demográficas de la cohorte muerte cardíaca súbita.

\begin{tabular}{|c|c|c|c|c|}
\hline Variable & $\begin{array}{l}\text { MS cardiaca } \\
(\mathrm{N}=490)\end{array}$ & $\begin{array}{c}\text { MS cardiaca } \\
\text { Explicada } \\
\text { (N=292) }\end{array}$ & $\begin{array}{l}\text { MS cardiaca } \\
\text { Inexplicada } \\
(N=198)\end{array}$ & $\mathbf{P}$ \\
\hline Edad, años (Media \pm DE) & $24 \pm 10$ & $27 \pm 8$ & $20 \pm 11$ & $<0,001$ \\
\hline Sexo femenino, $\mathbf{n}(\%)$ & $137(28)$ & $72(25)$ & $65(33)$ & 0,048 \\
\hline \multicolumn{5}{|l|}{ Actividad a la muerte } \\
\hline - Ejercicio, n/total (\%) & $56 / 365(15)$ & $34 / 199(17)$ & 22/166 (13) & 0,31 \\
\hline - Sueño, n/total (\%) & $139 / 365(38)$ & $59 / 199(30)$ & 80/166 (48) & $<0,001$ \\
\hline Intento de reanimación, n/total (\%) & $297 / 360(82)$ & $168 / 197(85)$ & 129/163 (79) & 0,13 \\
\hline Muerte durante noche ${ }^{\dagger}, \mathrm{n} /$ total $(\%)$ & $204 / 349(58)$ & $103 / 199(52)$ & $101 / 150(67)$ & 0,004 \\
\hline
\end{tabular}

${ }^{\dagger}$ La noche fue definida como las horas desde las 6 p.m. a las 6 a.m.

Conclusiones

La incidencia de MS sigue siendo baja en los menores de 35 años. El $40 \%$ de estas muertes no tiene una causa cardíaca clara. Se puede mejorar el diagnóstico en la víctimas de MS adicionando el

testeo genético y el seguimiento clínico de los familiares de primer orden de la víctima.

Fuentes de financiamiento: en su gran mayoría gubernamental y de fundaciones.

\section{Comentario}

La muerte súbita (MS) de un niño, adolescente o adulto joven, que gozaba previo al evento de una plena salud, es un evento devastador a nivel familiar y social. En el grupo etario de los menores de 35 años la MS se debía principalmente a cardiopatías hereditarias y congénitas (como la miocardiopatía hipertrófica, miocardiopatía arritmogénica, las anomalías de implantación de las arterias coronarias, entre otras). En los últimos años hubo una modificación epidemiológica de las causas, con un incremento creciente de las MS con corazón morfológicamente normal, llegando según las series del $29 \%$ al $40 \%$. A estas se las llama MS arrítmicas o por canalopatías (ejemplos son: el síndrome de QT largo, la taquicardia ventricular polimórfica catecolaminérgica y el síndrome de Brugada). Este cambio epidemiológico probablemente se deba a los efectos de los programas de rastreo de la MS (como en el caso del deporte) así como a las medidas de prevención secundaria como los cardiodesfibriladores implantables o los programas de acceso público a desfibriladores externos automáticos. Este artículo nos plantea una realidad en el manejo de la MS en menores de 35 años que por ahora nos es ajena. No existe ningún laboratorio argentino especializado en genética cardíaca en la actualidad, dado que realizar estudios moleculares requiere de la exportación del ADN. La buena noticia es que tenemos especialistas en consejo

genético cardíaco que tienen la capacidad de procesar y enviar las muestras, recibir el diagnóstico genético y dar el consejo familiar adecuado. Pero para avanzar hacia el futuro tenemos que consolidad el presente, y esto requiere de: 1) un registro nacional de MS, y sobre todo en menores de 35 a 40 años, estén o no relacionadas con el deporte; 2) que en todos los casos de MS se realicen las autopsias correspondientes, con estrictos protocolos de anatomía patológica cardíaca; 3) que en aquellos casos en que las autopsias sean negativas, se realice un perfil toxicológico; 4) que se almacenen muestras de tejido o sangre, las cuales pueden ser conservadas a temperatura ambiente por cuatro días o refrigeradas por siete días (se recomienda no congelar para realizar una autopsia molecular, indicación clase Ila Nivel C); y 5) que se realice un adecuado rastreo de los familiares de primer orden (de acuerdo a los consensos actuales).

\section{Conclusiones del comentador}

La incidencia de MS es baja en las personas menores de 35 años, y en una significativa proporción la causa en la MS queda sin aclarar. Aunque se podría mejorar el diagnóstico en la víctimas de MS implementando el testeo genético, en Argentina el acceso a estas pruebas es limitado.

Diego Iglesias [ Servicio de Cardiología del Hospital Italiano de Buenos Aires. diego.iglesias@ hospitalitaliano.org.ar ]

Iglesias D. Estudio prospectivo sobre muerte súbita de origen cardiovascular en niños y adultos jóvenes. Evid Act Pract Ambul. 2017;20(3):81. Jul-Sep. Comentado de: Bagnall R.D y col. A prospective study of sudden cardiac death among children and young adults. N Engl J Med 2016;374:2441-52. PMID: 27332903. 